\title{
A longitudinal study of foot ulceration and its risk factors in community- based patients with type 2 diabetes: The Fremantle Diabetes Study
}

\author{
Mendel Baba BPod (Hons) $)^{1,2}$ \\ Wendy A Davis $\mathrm{PhD}^{1}$ \\ Timothy M E Davis FRACP ${ }^{1}$
}

${ }^{1}$ School of Medicine and Pharmacology, University of Western Australia, Fremantle Hospital, Fremantle, Western Australia, Australia

${ }^{2}$ Podiatric Medicine Unit, The University of Western Australia, Crawley, Perth, Western Australia, Australia

Corresponding author: Professor T.M.E. Davis, University of Western Australia, School of Medicine and Pharmacology, Fremantle Hospital, PO Box 480, Fremantle, Western Australia 6959, Australia 


\section{Abstract}

Aims: To determine the prevalence and associates of foot ulcer, and the subsequent incidence and predictors of first-ever hospitalisation for this complication, in well-characterised community-based patients with type 2 diabetes.

Methods: Baseline foot ulceration was ascertained in 1,296 patients (mean age 64 years, $48.6 \%$ male, median diabetes duration 4.0 years) recruited to the longitudinal Fremantle Diabetes Study between 1993 and 1996. Incident hospitalisation for foot ulceration was monitored through validated data linkage until end-December 2010.

Results: At baseline, 16 participants (1.2\%) had a foot ulcer which was independently associated with intermittent claudication, peripheral sensory neuropathy (PSN) and diabetes duration $(P \leq 0.01)$. The incidence of hospitalisation for this complication in those without prior/prevalent foot ulceration was 5.21 per 1,000 patient-years. This rate and other published data suggest that 1 in 7-10 foot ulcers require hospitalisation. In a Cox proportional hazards model, intermittent claudication and PSN were significant independent predictors of time to admission with foot ulceration, in addition to retinopathy, cerebrovascular disease, $\mathrm{HbA}_{1 \mathrm{c}}$, alcohol consumption, renal impairment, peripheral arterial disease and pulse pressure $(P \leq 0.038)$.

Conclusions: These data confirm PSN as an important risk factor for foot ulceration but, in contrast to some other studies, peripheral arterial disease was also a major independent contributor. Associations between hospitalisation for foot ulcer and both retinopathy and raised pulse pressure suggest a role for local microvascular dysfunction, while alcohol may have non-neuropathic toxic effects on skin/subcutaneous structures. The multifactorial nature of foot ulceration complicating type 2 diabetes may have implications for its management.

Key words: type 2 diabetes, foot ulceration, risk factors 


\section{Introduction}

Foot ulcers contribute significantly to the morbidity, mortality and cost associated with diabetes [8]. Accurate estimates of the prevalence and incidence of foot ulceration complicating type 2 diabetes have, however, been difficult to obtain [22, 30]. Available data from largely primary care studies suggest that the point prevalence of an active ulcer is up to $1.8 \%[17,25]$, with an annual incidence ranging from $1.0 \%$ to $4.1 \%$ [37]. Such estimates can, however, be influenced by how foot ulcers are defined and ascertained, as well as by racial/ethnic differences in propensity to foot ulceration $[2,26]$ and between-sample differences in the management of diabetes and associated foot disease that are strongly influenced by socio-economic and behavioural factors [30].

Similarly, risk factors for diabetic foot ulcers have been incompletely characterised [13, 14, 32]. In recent meta-analyses $[14,32]$, diagnostic tests and physical signs that detect peripheral sensory neuropathy (PSN) and excessive plantar pressure were consistently associated with future diabetic foot ulceration, but the role of other candidate risk factors including $\mathrm{HbA}_{1 \mathrm{c}}$ and ankle brachial index (ABI) were not. Differences in methodology including design (retrospective vs prospective), sources of patients (clinic vs community), attrition rates, durations of follow-up, definitions and ascertainment of foot ulcer, standardisation of data collection, cut-points for interpretation of diagnostic tests, and availability of potential explanatory variables for multivariate assessment of independent associates, are all barriers to effective pooling of data $[14,32]$. Indeed, very few individual studies have included a full range of predictive variables in their analyses [32], a deficiency that has prompted international collaboration aimed at performing a more detailed systematic review [13]. 
Issues with ascertainment are highlighted by the observation that a significant proportion of diabetic patients can develop foot ulcers, including those that persist for more than three weeks, that heal without healthcare system intervention [21]. This reflects patient delay in seeking help $[35,36]$, especially by those who do not regard an ulcer as a serious complication of diabetes [36]. Given the problems associated with complete identification of all ulcers in a longitudinal natural history study and the inconsistent findings from previous studies, the aims of the present study were to i) determine the prevalence and associates of foot ulceration in patients with type 2 diabetes from a large representative community-based cohort detected through active screening, and ii) identify the incidence and predictors of all foot ulceration severe enough to require hospitalisation during up to 17 years of follow-up of the same cohort.

\section{Subjects, Materials and Methods}

\section{Patients}

The Fremantle Diabetes Study Phase I (FDS1) is a longitudinal observational cohort study of patients from a postcode-defined urban community of 120,097 people. Descriptions of recruitment, sample characteristics including classification of diabetes type and details of non-recruited patients have been published elsewhere [15]. Of 2,258 diabetic patients identified from a variety of sources between April 1993 and June 1996, 1,426 (63\%) were recruited to FDS1 and 1,296 had clinically-diagnosed type 2 diabetes. Eligible patients who declined participation were a mean of 1.4 years older than participants, but their sex distribution, the proportion with type 2 diabetes and their use of blood glucose-lowering 
therapies were similar [15]. The FDS1 protocol was approved by the Human Rights Committee at Fremantle Hospital and all subjects gave informed consent before participation.

\section{Clinical procedures}

Each FDS1 patient underwent comprehensive assessment at entry and was invited to return for similar assessment on an annual basis over a minimum of five years [15]. Questionnaire data included demographic, socioeconomic, diabetes-specific and general health data, with ethnic background based on self-selection, country/countries of birth and parents' birth and language(s) spoken at home. Patients provided fasting blood and urine samples for automated biochemical analyses in a single nationally-accredited laboratory. A standardized physical examination was performed by a trained registered nurse.

In relation to foot health, intermittent claudication was ascertained by determining whether pain in the calves came on during walking, caused the patient to slow down or stop, and resolved with rest. Examination included a detailed bilateral assessment including palpation for the pedal pulses (dorsalis pedis and posterior tibial), measurement of ankle brachial indices (ABI), assessment of PSN using the clinical features of the Michigan Neuropathy Screening Instrument (MNSI) [18], and general foot inspection to detect the presence or absence of ulceration (defined, for the purposes of the present study, as located at or below the level of the malleoli), deformity, corns or callus, skin fissures, infections and nail pathology.

Chronic complications were identified by standard criteria [16]. Peripheral sensory neuropathy (PSN) was defined as a score of $>2 / 8$ on the clinical portion of the MNSI. Peripheral arterial disease (PAD) was considered present if the ABI was $\leq 0.90$ on either leg 
or a diabetes-related amputation was present. Self-reported stroke and transient ischaemic attack were amalgamated with prior hospitalisations to define baseline cerebrovascular disease status. Patients were considered to have coronary heart disease if there was a selfreported history of, or hospitalisation for, myocardial infarction, angina, coronary artery bypass grafting, angioplasty and/or definite myocardial infarction on electrocardiogram. A subject was considered to have retinopathy if any grade of retinopathy, including maculopathy, was detected by direct and/or indirect ophthalmoscopy in one or both eyes and/or on more detailed assessment by an ophthalmologist. The estimated glomerular filtration rate (eGFR) was calculated using the Chronic Kidney Disease Epidemiology Collaboration equation [27].

\section{Hospitalisation for foot ulcer}

All hospital admissions, whether public or private, for foot ulceration were identified using relevant International Classification of Disease (ICD) procedure codes (ICD-9-CM and ICD10-AM). ICD-10-AM primary diagnosis codes E10.73, E11.73, E13.73 and E14.73 were coded as a foot ulcer with verification from the case-notes if required. Case-note review was also performed in all patients with ICD-10-AM codes L97 and I70.23, and, since ICD-9-CM codes did not include a specific diagnosis code for diabetes-related foot ulcer, those with codes 707.1 and 440.23 .

\section{Statistical analysis}

The computer package IBM SPSS Statistics 20 (IBM Corporation, Somers, NY, USA) was used. Data are presented as proportions, means $\pm \mathrm{SD}$, geometric mean (SD range), or in the case of variables that did not conform to a normal or ln-normal distribution, median (interquartile range $[\mathrm{IQR}]$ ). For independent samples, two way comparisons for proportions 
were by Fisher's exact test, Student's $t$ test for normally distributed variables, and the MannWhitney U-test for variables that were not normally distributed. A two-tailed $P$-value $<0.05$ was considered significant. Multiple logistic regression modelling was used to determine independent associates of prevalent foot ulceration. Cox proportional hazards modelling (forward conditional variable entry, entry and removal with $P<0.05$ and $>0.10$, respectively) was used to determine independent predictors of first-ever foot ulcer. All clinically plausible variables with $P<0.20$ were considered for model entry. In addition, MNSI-defined neuropathy was used as an indicator for all other measures of PSN. The crude incidence of first-ever diabetes related foot ulcer was determined in patients without foot ulcer at study entry by dividing the number of first-ever diabetes related foot ulcers after study entry, by the patient-years of follow up to first-ever ulcer or death or end-December 2010, whichever came first.

\section{Results}

At baseline, the mean age of the 1,296 patients was $64.0 \pm 11.3$ years, $48.6 \%$ were male, and they had a median [interquartile range] diabetes duration of 4.0 [1.0-9.0] years. Four participants had bilateral below-knee amputations at study entry and were excluded from further analysis. Sixteen of the remaining 1,292 patients had a foot ulcer identified at FDS entry, representing an active foot ulcer prevalence of $1.2 \%$ (95\% CI: $0.7 \%-2.1 \%)$. The characteristics of the patients with foot ulcers at baseline are compared with those without an ulcer in Table 1. Those with an ulcer were older, had longer diabetes duration, were more likely to be insulin-treated and taking antihypertensive medication and less likely to have exercised in the past two weeks. In relation to complications, they had higher urinary 
albumin:creatinine ratios and there were greater proportions with PSN, intermittent claudication, PAD and a history of vascular bypass surgery for PAD.

In multiple logistic regression analysis, the strongest independent associates of an active ulcer at baseline were intermittent claudication, PSN and diabetes duration (see Table 2). Antihypertensive therapy was weakly but positively associated with foot ulcer, consistent with confounding by indication.

Of the 1,272 type 2 patients without a prior history of hospitalisation for, or a prevalent, foot ulcer, $79(6.2 \%)$ had a first-ever hospital admission for foot ulcer during 15,154 patient-years of follow up. Of these 79 patients, 43 (54.4\%) were admitted for diabetes-associated foot ulcer as a primary diagnosis code. The remaining patients had a documented primary diagnosis other than foot ulcer but which included conditions (peripheral arterial disease or infection) closely related to foot ulceration as a secondary diagnosis code in a further seven patients $(8.9 \%)$. Twenty-nine other patients $(36.7 \%)$ were hospitalised for a reason other than a foot ulcer (mainly with complications of cardiovascular disease) but had an ulcer which required assessment and management.

The incidence of first-ever hospital admission for foot ulcer was 5.21 (95\% CI 4.13-6.50) per 1,000 patient-years. In men, the incidence was $6.01(4.33-8.12)$ per 1,000 patient-years compared with $4.53(3.19-6.25)$ per 1,000 patient years in women $(P=0.21)$. The mean age at which participants first developed a foot ulcer requiring inpatient care was $65.0 \pm 9.5$ years. Compared with participants who were not hospitalised for a foot ulcer during follow-up, those who were hospitalised had longer diabetes duration, worse glycaemic control and higher systolic and pulse pressures, and were more likely to have PSN, retinopathy, 
intermittent claudication, PAD, cerebrovascular disease and a history of vascular bypass surgery (see Table 3).

In a Cox proportional hazards model (see Table 4), independent predictors of time to firstever diabetes related foot ulcer were retinopathy, cerebrovascular disease, intermittent claudication, PSN, alcohol consumption, eGFR, PAD, $\mathrm{HbA}_{1 \mathrm{c}}$ and pulse pressure.

\section{Discussion}

The present data, from a large, well characterised cohort with long-duration follow-up, confirm the important contribution of PSN to foot ulceration [14, 32], but also show that peripheral vascular disease is a significant independent risk factor. Neuropathy detected by the clinical MNSI score was associated with a substantial increase in risk of a prevalent foot ulcer but, in the more informative prospective arm of the study, it also predicted a more than two-fold increase in incident hospitalisation for ulceration. The symptom of intermittent claudication was also a significant independent variable for both prevalent and incident foot ulcer, and other manifestations of $\mathrm{PAD}(\mathrm{ABI} \leq 0.90$ or a diabetes-related amputation $)$ and more widespread atherosclerosis (cerebrovascular disease and increased pulse pressure) were also predictors of incident hospitalisation for ulceration together with retinopathy, renal impairment, $\mathrm{HbA}_{1 \mathrm{c}}$ and alcohol consumption.

Our baseline active foot ulcer prevalence of $1.2 \%$ was lower than the $1.4-1.8 \%$ reported in other studies $[1,17,25]$. Although these latter estimates were within our $95 \% \mathrm{CI}\left(0.7 \%{ }^{-}\right.$ $2.1 \%$ ), it is likely that the lower prevalence in the present study was a reflection of the 
community-based nature of the FDS cohort compared with individuals who were recruited from primary or secondary care attendances. The incidence of hospitalisation for foot ulcer of 5.21 per 1,000 patient-years is understandably much lower than overall incidence rates of 3071 per 1,000 patient-years reported in a variety of other studies $[9,10,26]$. Similarly, cumulative annual incidence rates reported in the literature range from $1.0 \%$ to $4.1 \%$ [37] compared to only $0.6 \%$ in the present study. Given problems with ascertainment of all incident ulceration $[21,35,36]$, we restricted our cases to the severe end of the spectrum, specifically those requiring hospital admission. Based on our data and those of others $[1,9$, $10,17,25,26]$, we estimate that between one in seven and one in ten foot ulcers requires inpatient care.

Neuropathy, or markers of neuropathy including insensitivity to monofilament testing, absent ankle reflexes, elevated vibration perception threshold and composite indices other than MNSI such as the neuropathy disability score, have been consistently reported as a strong independent predictors of foot ulceration in the present and other studies $[1,3,9,14,23,32$, 39]. The association between markers of PAD and foot ulceration has been less clear [14]. Our data from one of the largest and longest-running studies to date show a robust link between PAD symptoms (intermittent claudication) and both prevalent and incident ulcer, supporting findings from a number of other studies [32]. For incident ulcer hospitalisation, PAD primarily ascertained through measurement of the ABI was also a significant independent risk factor. This suggests that symptoms of vascular insufficiency may be absent or not detected because of neuropathy in some patients at risk of foot ulceration, or that there are patients with calcified or incompressible arteries that do not have an $\mathrm{ABI} \leq 0.90$ but who have intermittent claudication. 
Other manifestations of macrovascular disease were independently associated with incident ulcer hospitalisation in our patients, specifically cerebrovascular disease and an increased pulse pressure. It is likely that there are patients in whom a presentation with a manifestation of more generalised atherosclerosis, such as with a stroke, precedes foot ulceration in contrast to other patients in whom PAD is the major macroangiopathic complication of type 2 diabetes. Alternatively, the associations with cerebrovascular disease and an increased pulse pressure are surrogates for a greater severity of PAD and thus progression of foot ulceration to the point where hospitalisation is required. Consistent with the present data, a self-reported history of stroke has been identified previously as an independent determinant of foot ulceration in a large Norwegian study [20].

Increased pulse pressure may predispose to complications such as foot ulceration through an increase in microvascular pressure due to underlying reduced elasticity of the larger arteries in combination with diabetes-related impaired vascular autoregulation [24]. In an Italian cohort study of more than 1,900 people, pulse pressure was also an independent risk factor for ulceration in association with other variables (including diabetes duration, $\mathrm{HbA}_{1 \mathrm{c}}$, PSN and lower limb arteriopathy) that were predictive in the present study [31].

Retinopathy was a strong predictor of incident hospitalisation with foot ulcer in our patients. Other studies have shown a direct [38] or indirect [10] association between retinopathy and foot ulceration. It is possible that shared risk factors with neuropathy and PAD, such as long diabetes duration, poor glycaemic control, dyslipidaemia and hypertension [5] may underlie co-linearity in the multivariate analyses, but there is also evidence that inadequate small blood vessel perfusion, which correlates with retinopathy, is a major cause of the inability to heal small wounds that eventually results in foot ulcer formation independently of neuropathy 
and macrovascular disease [34]. Reduced visual acuity associated with retinopathy may also result in delayed recognition of the presence and/or severity of a foot ulcer, thus increasing the likelihood of progression to hospitalisation.

Renal impairment was also an independent predictor in the incident foot ulcer Cox model. The same independent doubling of the risk of foot ulceration in patients with renal impairment has been shown by other authors [29], who postulated that hyperglycaemiaassociated damage to mesangial cells and podocytes, which have limited ability to replenish compared with cells of the dermis, might be an early marker of subsequent dermal skin leading to foot ulceration. However, patients with renal impairment may also be predisposed to foot ulceration through a variety of other factors such as leg oedema, anaemia and altered nutrition [33]. An increase in $\mathrm{HbA}_{1 \mathrm{c}}$ was a predictor of first-ever hospitalisation for foot ulceration in our cohort, consistent with other studies $[7,10,26]$. As this was independent of chronic micro- and macrovascular complications, it could reflect an adverse impact of foot ulceration on diabetes self-management (including lifestyle factors such as exercise as well as treatment adherence) prior to hospitalisation or the effects of foot ulceration and perhaps associated infection on prior glycaemic control.

There was a strong independent association between alcohol consumption and incident hospitalisation with foot ulcer in the present study. Alcohol has been found previously to be a risk factor for foot ulcer in several small-scale largely cross-sectional studies with $<200$ patients and limited other potential explanatory variables $[4,12,23,28]$. As the present association was independent of neuropathy, it is likely that the adverse effects of alcohol on nutrition and on wound healing may be responsible. We have found previously that alcohol consumption was also associated with tendon rupture in the FDS cohort [40], and alcohol- 
related inhibition of fibroblast proliferation and collagen synthesis may underlie both tendon injury and progression of foot ulceration.

Our study had limitations. We did not have either measures of excessive plantar pressure [14, 32] or a detailed assessment of the adequacy of footwear [6], factors that have been found to be prognostically important in other studies, but they are not routinely available in a usual care setting. Although our ascertainment of prevalent ulcer was relatively robust, the predictors of foot ulcers requiring hospitalisation may be different to those underlying less severe ulceration. The strengths of the present study include the prospective design, large patient numbers, long duration follow-up, detailed baseline assessment and capture of endpoints through a validated data linkage system [19] applied to a stable population base [11].

The present study, which is amongst the largest and longest duration longitudinal study yet undertaken, shows that foot ulceration is a common complication of type 2 diabetes that can progress to hospitalisation in a significant proportion of cases. Peripheral sensory neuropathy and PAD are major modifiable risk factors, confirming the results of previous studies $[1,3,9$, $14,23,32,39]$, but alcohol use, poor glycaemic control and renal impairment are other treatable precipitants. The associations between retinopathy, raised pulse pressure and foot ulceration raise the potentially important issue of local microvascular changes as contributors to pathogenesis, while alcohol may also have toxic effects on skin and subcutaneous structures that promote ulcer progression. All these risk factors should be considered carefully in the assessment and management of patients with type 2 diabetes who are at risk of, or who present with, foot ulceration. 


\section{Acknowledgements}

We thank the patients and FDS staff for their involvement in the study, and staff at PathWest Laboratory Medicine, Fremantle Hospital for laboratory tests. The FDS was funded by the Raine Foundation University of Western Australia. MB is supported by an Australian Postgraduate Award and University of Western Australia Top-Up Award. TMED is supported by a NHMRC Practitioner Fellowship.

\section{Duality of interest}

None declared. 


\section{References}

[1] C.A. Abbott, A.L. Carrington, H. Ashe, S. Bath, L.C. Every, J. Griffiths, A.W. Hann, A. Hussein, N. Jackson, K.E. Johnson, C.H. Ryder, R. Torkington, E.R. Van Ross, A.M. Whalley, P. Widdows, S. Williamson, A.J. Boulton, S. North-West Diabetes Foot Care, The North-West Diabetes Foot Care Study: incidence of, and risk factors for, new diabetic foot ulceration in a community-based patient cohort, Diabet Med, 19 (2002) 377-384.

[2] C.A. Abbott, A.P. Garrow, A.L. Carrington, J. Morris, E.R. Van Ross, A.J. Boulton, s. North-West diabetes foot care, Foot ulcer risk is lower in South-Asian and african-Caribbean compared with European diabetic patients in the U.K.: the North-West diabetes foot care study, Diabetes Care, 28 (2005) 1869-1875.

[3] C.A. Abbott, L. Vileikyte, S. Williamson, A.L. Carrington, A.J. Boulton, Multicenter study of the incidence of and predictive risk factors for diabetic neuropathic foot ulceration, Diabetes Care, 21 (1998) 1071-1075.

[4] N. Altenburg, P. Joraschky, A. Barthel, A. Bittner, K. Pohlmann, H. Rietzsch, S. Fischer, G. Mennicken, C. Koehler, S.R. Bornstein, Alcohol consumption and other psycho-social conditions as important factors in the development of diabetic foot ulcers, Diabet Med, 28 (2011) 168-174.

[5] D.A. Antonetti, R. Klein, T.W. Gardner, Diabetic retinopathy, N Engl J Med, 366 (2012) $1227-1239$.

[6] J. Apelqvist, J. Larsson, C.D. Agardh, The influence of external precipitating factors and peripheral neuropathy on the development and outcome of diabetic foot ulcers, J Diabet Complications, 4 (1990) 21-25.

[7] P.J. Bennett, A.E. Stocks, D.J. Whittam, Analysis of risk factors for neuropathic foot ulceration in diabetes mellitus, J Am Podiatr Med Assoc, 86 (1996) 112-116. 
[8] A.J. Boulton, The diabetic foot: grand overview, epidemiology and pathogenesis, Diabetes Metab Res Rev, 24 Suppl 1 (2008) S3-6.

[9] Boyko E, Ahroni J, Stensel V, Forsberg R, Davignon D, Smith D, A Prospective Study of Risk Factors for Diabetic Foot Ulcer: The Seattle Diabetic Foot Study, Diabetes Care, 22 (1999) 1036-1042.

[10] E.J. Boyko, J.H. Ahroni, V. Cohen, K.M. Nelson, P.J. Heagerty, Prediction of diabetic foot ulcer occurrence using commonly available clinical information: the Seattle Diabetic Foot Study, Diabetes Care, 29 (2006) 1202-1207.

[11] P.J. Bradshaw, K. Jamrozik, P. Jelfs, M. Le, Mobile Australians: a moving target for epidemiologists, Med J Aust, 172 (2000) 566.

[12] L.E. Bresater, L. Welin, B. Romanus, Foot pathology and risk factors for diabetic foot disease in elderly men, Diabetes Res Clin Pract, 32 (1996) 103-109.

[13] F. Crawford, C. Anandan, F.M. Chappell, G.D. Murray, J.F. Price, A. Sheikh, C.R. Simpson, M. Maxwell, G.P. Stansby, M.J. Young, C.A. Abbott, A.J. Boulton, E.J. Boyko, T. Kastenbauer, G.P. Leese, M. Monami, M. Monteiro-Soares, S.J. Rith-Najarian, A. Veves, N. Coates, W.J. Jeffcoate, N. Leech, T. Fahey, J. Tierney, Protocol for a systematic review and individual patient data meta-analysis of prognostic factors of foot ulceration in people with diabetes: the international research collaboration for the prediction of diabetic foot ulcerations (PODUS), BMC Med Res Methodol, 13 (2013) 22.

[14] F. Crawford, M. Inkster, J. Kleijnen, T. Fahey, Predicting foot ulcers in patients with diabetes: a systematic review and meta-analysis, QJM, 100 (2007) 65-86.

[15] T.M. Davis, D.G. Bruce, W.A. Davis, Cohort profile: the Fremantle Diabetes Study, Int J Epidemiol, 42 (2013) 412-421.

[16] W.A. Davis, P.E. Norman, D.G. Bruce, T.M. Davis, Predictors, consequences and costs of diabetes-related lower extremity amputation complicating type 2 diabetes: the Fremantle 
Diabetes Study, Diabetologia, 49 (2006) 2634-2641.

[17] J.J. de Sonnaville, L.P. Colly, D. Wijkel, R.J. Heine, The prevalence and determinants of foot ulceration in type II diabetic patients in a primary health care setting, Diabetes Res Clin Pract, 35 (1997) 149-156.

[18] E.L. Feldman, M.J. Stevens, P.K. Thomas, M.B. Brown, N. Canal, D.A. Greene, A practical two-step quantitative clinical and electrophysiological assessment for the diagnosis and staging of diabetic neuropathy, Diabetes Care, 17 (1994) 1281-1289.

[19] C.D. Holman, A.J. Bass, D.L. Rosman, M.B. Smith, J.B. Semmens, E.J. Glasson, E.L. Brook, B. Trutwein, I.L. Rouse, C.R. Watson, N.H. de Klerk, F.J. Stanley, A decade of data linkage in Western Australia: strategic design, applications and benefits of the WA data linkage system, Aust Health Rev, 32 (2008) 766-777.

[20] Iversen M, Midthjell K, Ostbye T, Tell G, Clipp E, Sloane R, Nortvedt M, Uhlving S, Hanestad B, History of and factors associated with diabetic foot ulcers in Norway: The NordTrondelag Health Study, Scandinavian Journal of Public Health, 36 (2007) 62-68.

[21] M.M. Iversen, K. Midthjell, T. Ostbye, G.S. Tell, E. Clipp, R. Sloane, M.W. Nortvedt, S. Uhlving, B.R. Hanestad, History of and factors associated with diabetic foot ulcers in Norway: the Nord-Trondelag Health Study, Scand J Public Health, 36 (2008) 62-68. [22] W.J. Jeffcoate, K.G. Harding, Diabetic foot ulcers, Lancet, 361 (2003) 1545-1551. [23] T. Kastenbauer, S. Sauseng, G. Sokol, M. Auinger, K. Irsigler, A prospective study of predictors for foot ulceration in type 2 diabetes, J Am Podiatr Med Assoc, 91 (2001) 343-350. [24] S.T. Knudsen, P.L. Poulsen, K.W. Hansen, E. Ebbehoj, T. Bek, C.E. Mogensen, Pulse pressure and diurnal blood pressure variation: association with micro- and macrovascular complications in type 2 diabetes, Am J Hypertens, 15 (2002) 244-250.

[25] S. Kumar, H.A. Ashe, L.N. Parnell, D.J. Fernando, C. Tsigos, R.J. Young, J.D. Ward, A.J. Boulton, The prevalence of foot ulceration and its correlates in type 2 diabetic patients: a 
population-based study, Diabet Med, 11 (1994) 480-484.

[26] L.A. Lavery, D.G. Armstrong, R.P. Wunderlich, J. Tredwell, A.J. Boulton, Diabetic foot syndrome: evaluating the prevalence and incidence of foot pathology in Mexican Americans and non-Hispanic whites from a diabetes disease management cohort, Diabetes Care, 26 (2003) 1435-1438.

[27] A.S. Levey, L.A. Stevens, C.H. Schmid, Y.L. Zhang, A.F. Castro, H.I. Feldman, J.W. Kusek, P. Eggers, F. Van Lente, T. Greene, J. Coresh, null, A new equation to estimate glomerular filtration rate, Annals of internal medicine, 150 (2009) 604-612.

[28] I. Mantey, A.V. Foster, S. Spencer, M.E. Edmonds, Why do foot ulcers recur in diabetic patients?, Diabet Med, 16 (1999) 245-249.

[29] D.J. Margolis, O. Hofstad, H.I. Feldman, Association between renal failure and foot ulcer or lower-extremity amputation in patients with diabetes, Diabetes Care, 31 (2008) 13311336.

[30] D.J. Margolis, W. Jeffcoate, Epidemiology of foot ulceration and amputation: can global variation be explained?, Med Clin North Am, 97 (2013) 791-805.

[31] M. Monami, M. Vivarelli, C.M. Desideri, C. Colombi, N. Marchionni, E. Mannucci, Pulse pressure and prediction of incident foot ulcers in type 2 diabetes, Diabetes Care, 32 (2009) 897-899.

[32] M. Monteiro-Soares, E.J. Boyko, J. Ribeiro, I. Ribeiro, M. Dinis-Ribeiro, Predictive factors for diabetic foot ulceration: a systematic review, Diabetes Metab Res Rev, 28 (2012) 574-600.

[33] A. Ndip, M.K. Rutter, L. Vileikyte, A. Vardhan, A. Asari, M. Jameel, H.A. Tahir, L.A. Lavery, A.J. Boulton, Dialysis treatment is an independent risk factor for foot ulceration in patients with diabetes and stage 4 or 5 chronic kidney disease, Diabetes Care, 33 (2010) $1811-1816$. 
[34] B.T. Ngo, K.D. Hayes, D.J. DiMiao, S.K. Srinivasan, C.J. Huerter, M.S. Rendell, Manifestations of cutaneous diabetic microangiopathy, Am J Clin Dermatol, 6 (2005) 225237.

[35] L. Prompers, M. Huijberts, J. Apelqvist, E. Jude, A. Piaggesi, K. Bakker, M. Edmonds, P. Holstein, A. Jirkovska, D. Mauricio, G.R. Tennvall, H. Reike, M. Spraul, L. Uccioli, V. Urbancic, K. Van Acker, J. Van Baal, F. Van Merode, N. Schaper, Delivery of care to diabetic patients with foot ulcers in daily practice: results of the Eurodiale Study, a prospective cohort study, Diabet Med, 25 (2008) 700-707.

[36] A.P. Sanders, L.G. Stoeldraaijers, M.W. Pero, P.J. Hermkes, R.C. Carolina, P.J. Elders, Patient and professional delay in the referral trajectory of patients with diabetic foot ulcers, Diabetes Res Clin Pract, 102 (2013) 105-111.

[37] N. Singh, D.G. Armstrong, B.A. Lipsky, Preventing foot ulcers in patients with diabetes, JAMA, 293 (2005) 217-228.

[38] D.P. Walters, W. Gatling, M.A. Mullee, R.D. Hill, The distribution and severity of diabetic foot disease: a community study with comparison to a non-diabetic group, Diabet Med, 9 (1992) 354-358.

[39] M.J. Young, J.L. Breddy, A. Veves, A.J. Boulton, The prediction of diabetic neuropathic foot ulceration using vibration perception thresholds. A prospective study, Diabetes Care, 17 (1994) 557-560.

[40] M.H. Zakaria, W.A. Davis, T.M. Davis, Incidence and predictors of hospitalization for tendon rupture in Type 2 diabetes: the Fremantle Diabetes Study, Diabet Med, (2014) in press. 
Table 1. Baseline characteristics of Fremantle Diabetes Study patients with type 2 diabetes by foot ulcer status.

\begin{tabular}{|c|c|c|c|}
\hline & No foot ulcer & Foot ulcer & $P$-value \\
\hline Number & 1276 & 16 & \\
\hline Age (years) & $63.9 \pm 11.3$ & $73.4 \pm 8.4$ & 0.001 \\
\hline Male $(\%)$ & 48.7 & 37.5 & 0.46 \\
\hline Married/de facto relationship (\%) & 65.8 & 50.0 & 0.19 \\
\hline Ethnicity (Anglo-Celt/Southern European/Other; \%) & $61.3 / 17.9 / 20.8$ & $62.5 / 12.5 / 25.0$ & 0.88 \\
\hline Education level (\% greater than primary level) & 74.0 & 68.8 & 0.58 \\
\hline Alcohol consumption (standard drinks/day) & $0[0-0.8]$ & $0[0-0]$ & 0.12 \\
\hline Smoking status (never/ex-/current; \%) & $45.0 / 40.0 / 15.0$ & $20.0 / 53.3 / 26.7$ & 0.09 \\
\hline Any exercise in the past 2 weeks (\%) & 72.5 & 43.8 & 0.02 \\
\hline Diabetes duration (years) & $4.0[1.0-9.0]$ & $13.0[10.0-23.0]$ & $<0.001$ \\
\hline Fasting plasma glucose $(\mathrm{mmol} / \mathrm{L})$ & $8.5[6.9-10.8]$ & $8.8[6.4-11.7]$ & 0.74 \\
\hline $\mathrm{HbA}_{1 \mathrm{c}}(\%)$ & $7.4[6.4-8.8]$ & 8.0 [6.5-9.7] & 0.35 \\
\hline $\mathrm{HbA}_{\mathrm{lc}}(\mathrm{mmol} / \mathrm{mol})$ & $57[46-73]$ & $64[48-83]$ & 0.35 \\
\hline Diabetes treatment (diet/oral agents/insulin \pm oral; \%) & $32.4 / 56.1 / 11.6$ & $6.3 / 50.0 / 43.8$ & 0.001 \\
\hline Prior diabetes education (\%) & 67.7 & 75.0 & 0.79 \\
\hline Prior podiatry attendance $(\%)$ & 30.2 & 50.0 & 0.10 \\
\hline Height (m) & $1.65 \pm 0.10$ & $1.63 \pm 0.09$ & 0.33 \\
\hline Body mass index $\left(\mathrm{kg} / \mathrm{m}^{2}\right)$ & $29.5 \pm 5.5$ & $27.7 \pm 3.7$ & 0.18 \\
\hline Abdominal obesity by waist circumference (\%) & 64.7 & 56.3 & 0.60 \\
\hline Systolic blood pressure (mmHg) & $151 \pm 24$ & $153 \pm 31$ & 0.73 \\
\hline Diastolic blood pressure (mmHg) & $80 \pm 11$ & $76 \pm 11$ & 0.08 \\
\hline Pulse pressure (mmHg) & $70 \pm 20$ & $77 \pm 25$ & 0.17 \\
\hline Anti-hypertensive treatment (\%) & 50.3 & 87.5 & 0.004 \\
\hline Lipid-modifying therapy (\%) & 10.9 & 0.0 & 0.40 \\
\hline Aspirin therapy $(\%)$ & 21.9 & 31.3 & 0.37 \\
\hline Total serum cholesterol $(\mathrm{mmol} / \mathrm{L})$ & $5.5 \pm 1.1$ & $5.6 \pm 1.5$ & 0.62 \\
\hline Serum HDL-cholesterol (mmol/L) & $1.1 \pm 0.3$ & $1.1 \pm 0.3$ & 0.43 \\
\hline Serum LDL-cholesterol $(\mathrm{mmol} / \mathrm{L})$ & $3.4 \pm 0.9$ & $3.6 \pm 1.3$ & 0.39 \\
\hline Serum triglycerides $(\mathrm{mmol} / \mathrm{L})$ & $1.9(1.1-3.3)$ & $1.6(1.0-2.7)$ & 0.37 \\
\hline Urinary albumin:creatinine (mg/mmol) & $3.1(0.7-13.4)$ & $4.9(1.7-14.2)$ & 0.048 \\
\hline $\begin{array}{l}\text { Estimated glomerular filtration rate } \\
<60 \mathrm{~mL} / \mathrm{min} / 1.73 \mathrm{~m}^{2}(\%)\end{array}$ & 34.3 & 56.3 & 0.11 \\
\hline Retinopathy (any) (\%) & 16.1 & 33.3 & 0.08 \\
\hline Peripheral sensory neuropathy (\%) & 30.0 & 92.9 & $<0.001$ \\
\hline Self-reported intermittent claudication (\%) & 13.1 & 81.3 & $<0.001$ \\
\hline Peripheral arterial disease (\%) & 28.8 & 57.1 & 0.03 \\
\hline Cerebrovascular disease (\%) & 9.8 & 12.5 & 0.67 \\
\hline Ischaemic heart disease (\%) & 29.2 & 43.8 & 0.27 \\
\hline History of vascular bypass before first visit (\%) & 1.0 & 12.5 & 0.01 \\
\hline
\end{tabular}

Values are proportions, means $\pm \mathrm{SD}$, geometric mean (SD range), or median [interquartile range] 
Table 2. Significant independent associates of foot ulcer at study entry.

\begin{tabular}{lcc}
\hline & Odds ratio $(95 \% \mathrm{CI})$ & $P$-value \\
\hline Intermittent claudication & $17.24(3.66-81.23)$ & $<0.001$ \\
Diabetes duration (for increase of 5 years) & $1.58(1.12-2.23)$ & 0.009 \\
Peripheral sensory neuropathy & $15.84(1.95-128.81)$ & 0.010 \\
Antihypertensive therapy & $11.16(1.13-95.44)$ & 0.028 \\
\hline
\end{tabular}


Table 3. Baseline characteristics of Fremantle Diabetes Study participants with type 2 diabetes by incident foot ulcer status during follow-up.

\begin{tabular}{|c|c|c|c|}
\hline & No incident foot ulcer & Incident foot ulcer & $P$-value \\
\hline Number & 1,193 & 79 & \\
\hline Age (years) & $63.8 \pm 11.4$ & $65.5 \pm 9.4$ & 0.13 \\
\hline Male (\%) & 48.2 & 53.2 & 0.42 \\
\hline Married/de facto relationship (\%) & 66.2 & 60.3 & 0.32 \\
\hline Ethnicity (Anglo-Celt/Southern European/Other; \%) & $61.3 / 617.7 / 21.0$ & $62.0 / 20.3 / 17.7$ & 0.71 \\
\hline Education level (\% greater than primary level) & 73.8 & 76.6 & 0.69 \\
\hline Alcohol consumption (standard drinks/day) & $0.0[0.0-0.4]$ & $0.0[0-1.5]$ & 0.18 \\
\hline Smoking status (never/ex-/current; \%) & $45.5 / 39.8 / 14.7$ & $38.5 / 42.3 / 19.2$ & 0.36 \\
\hline Any exercise in the past 2 weeks $(\%)$ & 72.5 & 73.7 & 0.90 \\
\hline Diabetes duration (years) & $4.0[0.9-8.0]$ & $5.4[2.8-12.0]$ & 0.001 \\
\hline Fasting plasma glucose $(\mathrm{mmol} / \mathrm{L})$ & $8.3[6.8-10.7]$ & $9.4[7.4-12.2]$ & 0.015 \\
\hline $\mathrm{HbA}_{1 \mathrm{c}}(\%)$ & $7.4[6.4-8.8]$ & $7.9[6.9-9.6]$ & 0.003 \\
\hline $\mathrm{HbA}_{1 \mathrm{c}}(\mathrm{mmol} / \mathrm{mol})$ & $57[46-73]$ & $63[52-81]$ & 0.003 \\
\hline Diabetes treatment (diet/oral agents/insulin \pm oral; \%) & $33.3 / 55.6 / 11.0$ & 19.2/61.5/19.2 & 0.009 \\
\hline Prior diabetes education $(\%)$ & 68.2 & 60.8 & 0.17 \\
\hline Prior podiatry attendance $(\%)$ & 29.7 & 34.6 & 0.37 \\
\hline Height (m) & $164.7 \pm 9.7$ & $166.7 \pm 10.0$ & 0.08 \\
\hline Body mass index $\left(\mathrm{kg} / \mathrm{m}^{2}\right)$ & $29.6 \pm 5.5$ & $29.8 \pm 5.3$ & 0.65 \\
\hline Abdominal obesity by waist circumference $(\%)$ & 64.1 & 72.2 & 0.18 \\
\hline Systolic blood pressure (mmHg) & $150 \pm 24$ & $157 \pm 20$ & 0.009 \\
\hline Diastolic blood pressure (mmHg) & $80 \pm 11$ & $81 \pm 10$ & 0.48 \\
\hline Pulse pressure (mmHg) & $70 \pm 20$ & $76 \pm 17$ & 0.007 \\
\hline Anti-hypertensive treatment (\%) & 50.1 & 53.2 & 0.64 \\
\hline Total serum cholesterol (mmol/L) & $5.5 \pm 1.1$ & $5.5 \pm 1.1$ & 0.71 \\
\hline Serum HDL-cholesterol (mmol/L) & $1.06 \pm 0.32$ & $1.06 \pm 0.34$ & 0.95 \\
\hline Serum LDL-cholesterol (mmol/L) & $3.44 \pm 0.90$ & $3.43 \pm 0.92$ & 0.85 \\
\hline Serum triglycerides $(\mathrm{mmol} / \mathrm{L})$ & $1.9(1.09-3.3)$ & $2.0(1.2-3.4)$ & 0.09 \\
\hline Lipid-modifying therapy (\%) & 11.0 & 10.1 & 1.00 \\
\hline Aspirin therapy (\%) & 22.0 & 19.0 & 0.67 \\
\hline Urinary albumin:creatinine (mg/mmol) & $3.0(0.7-12.8)$ & $5.2(1.1-25.2)$ & 0.001 \\
\hline $\begin{array}{l}\text { Estimated glomerular filtration rate } \\
<60 \mathrm{~mL} / \mathrm{min} / 1.73 \mathrm{~m}^{2}(\%)\end{array}$ & 33.2 & 49.4 & 0.006 \\
\hline Retinopathy (any) (\%) & 14.1 & 42.9 & $<0.001$ \\
\hline Peripheral sensory neuropathy (\%) & 29.0 & 43.5 & 0.014 \\
\hline Self-reported intermittent claudication (\%) & 12.1 & 24.1 & 0.005 \\
\hline Peripheral arterial disease $(\%)$ & 27.7 & 43.6 & 0.004 \\
\hline Cerebrovascular disease $(\%)$ & 9.3 & 17.7 & 0.029 \\
\hline Ischaemic heart disease $(\%)$ & 29.0 & 31.6 & 0.61 \\
\hline History of vascular bypass before first visit (\%) & 0.8 & 3.8 & 0.03 \\
\hline
\end{tabular}

Values are proportions, means $\pm \mathrm{SD}$, geometric mean (SD range), or median [interquartile range] 
Table 4. Cox proportional hazards model of baseline predictors of time to first-ever admission for diabetes-related foot ulceration during follow up.

\begin{tabular}{lcc}
\hline & Hazard ratio $(95 \% \mathrm{CI})$ & $P$-value \\
\hline Any retinopathy & $3.86(2.26-6.59)$ & $<0.001$ \\
Cerebrovascular disease & $3.76(1.97-7.19)$ & $<0.001$ \\
Intermittent claudication & $2.77(1.52-5.04)$ & 0.001 \\
Peripheral sensory neuropathy & $2.24(1.35-3.71)$ & 0.002 \\
$\mathrm{HbA}_{1 \mathrm{c}}$ (for a 1.0\% increase) & $1.22(1.07-1.40)$ & 0.003 \\
Alcohol consumption (for a 1 standard drink/day increase) & $1.16(1.05-1.27)$ & 0.003 \\
Estimated glomerular filtration rate $<60 \mathrm{~mL} / \mathrm{min} / 1.73 \mathrm{~m}^{2}$ & $2.12(1.30-3.51)$ & 0.004 \\
Peripheral arterial disease & $1.85(1.10-3.13)$ & 0.021 \\
Pulse pressure (for a $5 \mathrm{mmHg}$ increase) & $1.07(1.00-1.14)$ & 0.038 \\
\hline
\end{tabular}

